\title{
Data driven process for the energy assessment of building envelope retrofits
}

\author{
Roberto Garay-Martinez ${ }^{1, *}$, Beñat Arregi ${ }^{1}$, Mikel Lumbreras ${ }^{1}$, Belén Zurro ${ }^{2}$, Jose Manuel Gonzalez ${ }^{2}$, Jose Luis \\ Hernandez $z^{3}$ \\ ${ }^{1}$ TECNALIA, Basque Research and Technology Alliance (BRTA), Astondo bidea 700, 48160, Derio, Spain \\ ${ }^{2}$ Universidad de Burgos, Calle Don Juan de Austria, s/n, 09001 Burgos, Spain \\ ${ }^{3}$ CARTIF, Dirección, Parque Tecnológico Boecillo 205, 47151, Boecillo, Spain
}

\begin{abstract}
In the last decades, a growing industry has been created in relation to building envelope retrofits. Linked to the lack of financial capacity of many building owners, innovative instruments such as energy performance contracts have been promoted by public bodies. This kind of instruments require of detailed energy assessment processes in order to define the expected heat load reduction and the associated economic flows between building owners and Energy Services Companies. When dealing with building envelopes, existing methods for building envelope heat loss characterization require of substantial efforts in terms of equipment and time, which makes them difficult to apply in real practice. In this paper, a novel method is proposed based on whole-building heat load assessment by means of heat meters, and analytical calculations of building envelope transmission heat load coefficients. This method, which requires minimal or no additional equipment, can be used over historical data from District Heating systems. It assigns a specific load fraction to building envelope heat transfer and allows to assess the expected reduction due to the building envelope retrofit. Numerical and experimental data is presented based on an educational building in the city of Burgos, Spain.
\end{abstract}

\section{Introduction}

In the frame of increasingly frequent warnings on the Global Warming and its effects, many Climate emergency declarations have been issued by many public bodies across the globe. The EU declaration of $28 / 11 / 2019$ [1] requested to mitigation measures to limit the global warning to $1.5^{\circ} \mathrm{C}$.

Considering the current greenhouse emitting activities and energy consumption profile, energy use in buildings is one of the sectors where de-carbonisation measures should be taken. In fact, EU has a longestablished tradition towards delivering increasingly demanding regulations and building codes towards the reduction of energy use in buildings [2,3].

However, it shall be considered that Europe is a consolidated region, where most of the building stock is meant to stay in the long term. Considering this, measures towards energy efficiency and the integration of renewable energy sources need to be targeted at building retrofits.

The construction sector is considered to be highly stable, with low penetration of innovations/improvements. This is due to a myriad of reasons. Among the main reasons for this is the required investment levels for any relevant retrofit job (typical renovation rates are $1-2 \% / y e a r)$, and the unawareness of building owners towards energy efficiency. Considering all this, public bodies have delivered specific enabling measures and fostered the development of energy performance-based contracts. In energy performance contracts (EPC), it is typical that a specific Energy Services Company (ESCO) waives totally or partially upfront costs in building energy retrofit works. ESCOs are then paid back based on the performance levels of the retrofit as established in the EPC.

Considering that payments in EPCs are linked to the actual performance of the retrofit, there is a typical need for the third-party assessment of the actually achieved performance. Specific protocols such as the International Performance Measurement and Verification Protocol (IPMVP)[4] deliver criteria and protocols for the assessment of these performance levels based on in-use data. of buildings.

Measurement and Verification (M\&V) protocols have been heavily introduced within the facility management sector, as required in multi-year maintenance and upgrade contracts with public and private facility owners. However, this integration level has not been achieved in building envelope insulation works.

Although reasons for this are not fully clear, the high atomization of the construction sector, technical difficulties for the effective determination of envelope insulation levels, and relatively lower tradition towards EPC may be inferred.

\footnotetext{
* Corresponding author: roberto.garay@tecnalia.com
} 
There is only a limited number of possible methods for the on-site assessment of heat transfer and energy use in buildings. Energy signature methods [5] deliver relation between the actual use of energy and climate conditions, but do not deliver the specific relation of energy use towards a specific energy flow (e.g. walls, windows, etc.). U-value measurements [6] deliver the actual building envelope insulation level, but do not relate this insulation level with the actual use of energy in the building for a specific period (e.g. one month), due to the non-linearities in heat loads in buildings.

Considering the aforementioned facts, among others, there is a well-established perception of ineffective design, construction, and measurement techniques in all fields with regards to the energy performance of buildings. In some countries, the concept of "performance gap" [7] has been established. But considering issues such as the climate emergency, increasingly stringent building codes and the need for accountability of contractors in large investments, there is a need for the improvement of M\&V processes. Both for self-funded projects and those delivered under EPC schemes.

In this paper, a hybrid method based on energy signature processes is presented. The novelty of this method lies on the calculation of the Heat Loss Coefficient of the building by means of a-priori knowledge and on-site U-value measurements.

By doing so, this method delivers both the actual performance level of insulation systems (U-value), and the real energy savings allocated to the improvement of insulation levels.

This method is linked to increasingly common heat metering systems. These systems, traditionally used in District Heating (DH) and large industrial complexes are increasingly common in HVAC systems in buildings. Modern systems commonly deliver hourly heat consumption data. In [8], a big data application for the DH system in Tartu is delivered, together with energy signature assessment methods. By using these meters, the requirements for intrusive metering of energy performance of buildings is avoided.

Data from the meters is complemented with U-value measurements and building envelope scale. These measurements are delivered according to $[9,10]$, and commonly require the installation of $\sim 6$ sensors during a 1-2 week measurement campaign. This is considered to be an acceptable level of intrusion for the M\&V process. The method is applied over an educational building in Burgos, Spain. The partial retrofit of this building was conducted within EU h2020 project E2VENT [11]. Heat meter data for the pre- and post-retrofit has been used in this process. Greater detail on this process is available at [12].

\section{Energy Signature Methods}

Energy signature methods determine energy consumption with regards to boundary conditions. Typical energy consumption data are thermal or electrical loads associated to space heating or spacecooling. These are typically correlated with outdoor temperature and solar irradiation. In some cases, more complex formulae incorporate indoor temperature and wind speed. Also, in some cases, complex variables such as indoor-outdoor temperature difference, or Degree-Days are used as explanatory variables.

Degree-Day methods commonly account for positive differences between a threshold ambient temperature and the actual ambient temperature as the independent variable in energy signature methods. These methods are computed as daily mean values, considering that usage patterns and the inertia of buildings is commonly in that range of time. The most commonly considered threshold value is $15^{\circ} \mathrm{C}$. Typically, linear relations are sought, but other more complex formulations are also possible. In eq (1), the simplest formulation of energy signature method is presented. This method is re-formulated to take Heating Degree-Days as independent variable in (2)

$$
\begin{gathered}
E=C_{0}+C_{1} * T_{e x t} \\
E=C_{0}+C_{1} * H D D
\end{gathered}
$$

Energy signature methods do not deliver a causal relationship of energy loads with regards specific energy transfer paths (i.e. heat transfer through walls, infiltration heat loss, etc.). Typical sampling frequency to apply this method are 1-day or 1-month.

\section{On-Site Heat Transfer Assessment of Building Envelopes}

Building envelope U-values deliver a clear metric on the insulation level of a construction. U-values for envelope systems can be obtained at design stage by means of [13, $14,15]$. Experimental assessment at laboratory scale can deliver U-values for fenestration and curtain wall systems [16]. However, due to problems with regards to solar radiation, only opaque envelopes can be assessed by on-site u-value measurements. On-site assessment methods are performed based on $[9,10]$, by means of localized measurements. Typical measurement campaign is $1-2$ weeks.

Most commonly used variants of the aforementioned standards are steady state formulations based on timeaveraged data. This allows to filter thermal inertia of walls. The formulation is presented in eq (3).

$$
U=Q / \Delta T
$$

Transient analysis are possible, but only seldom used. These methods deliver the actual quality of the insulation layer of building envelopes, but this information can not be directly correlated with energy consumption data.

\section{Proposed data-driven method}

The proposed hybrid energy-signature and U-value assessment method delivers a joint assessment of 
thermal insulation (U-value) and energy performance (allocated energy load) of a building envelope insulation system. For doing this, the following process is followed:

- The U-value of a building envelope is calculated (design stage) or measured

- If compound retrofits are made (e.g. wall insulation+ window replacement), a joint calculation of the Heat loss Coefficient (HLC) is made by means of [17]

- The energy consumption of a building and the associated boundary conditions are measured for a relevant period. Typical M\&V protocols [4] require 1year measurement process

- Energy signature assessment is performed over the heat loads. The linear relationship towards outdoor temperature is obtained. (e.g. $\mathrm{C}_{1}$ in (1))

- The U-value or HLC is converted into a comparable metric $\mathrm{C}_{1}, \mathrm{C}_{1}$ HLC. Typical conversions require to convert power (W) into Energy ( $\mathrm{J}, \mathrm{Wh}$, etc.), and specific (per $\mathrm{m}^{2}$ ) into total (per total building envelope) metrics. For this process, the sampling period, and total/partial surfaces are considered.

- Then $\mathrm{C}_{1}$ in equation (2) is converted into two independent coefficients as presented in (4) and (5):

$$
\begin{gathered}
C_{1}=C_{I_{-} H L C}+C_{I_{-} \text {OTHER }} \\
E=C_{0}+C_{I_{-} H L C} * H D D+C_{I_{-} \text {OTHER }} * H D D
\end{gathered}
$$

- Equation (4) is applied for the pre-retrofit case

- The energy performance of the post-retrofit case based on a-priori knowledge (Heat loss coefficients and other coefficients in (5). This means that $\mathrm{C}_{1 \_\mathrm{HLC}}$ is modified in (5), while $\mathrm{C}_{0}$ and $\mathrm{C}_{1}$ _otHER remain constant.

- The deviation of the actual performance of the postretrofit case when compared to the one calculated with apriori knowledge is taken into assessed.

\section{Case study}

The method is applied over Building 3 of the Faculty of Nursing and Health Sciences of the University of Burgos, Spain. This building was originally built in 1880 to serve as a Military Hospital. It consists of a single floor with an area of $545.49 \mathrm{~m}^{2}$, composed of five classrooms and other auxiliary rooms. The main facades of the building are oriented north and south. Within [11] a partial retrofit of one room was performed. External insulation was installed.

The original walls are massive load-bearing stone masonry walls of approximately $62 \mathrm{~cm}$ wide, which present certain irregularities due to the different shape of the pieces that form the facades. The union of the masonry was made with lime-cement mortar. Note the existence of double windows with wood frames and simple glazing.

The building comprises a suspended floor above a ventilated underfloor space. The supporting structure of the roof is formed with trusses made of wood and steel, on which wood purlins are also supported. The waterproofing is formed by wooden boards and flat ceramic tiles. A suspended ceiling system incorporates a thermal insulation layer composed of $8 \mathrm{~cm}$ thick mineral wool panels. This insulation was placed in one of the renovations that the building has seen throughout its years of use.

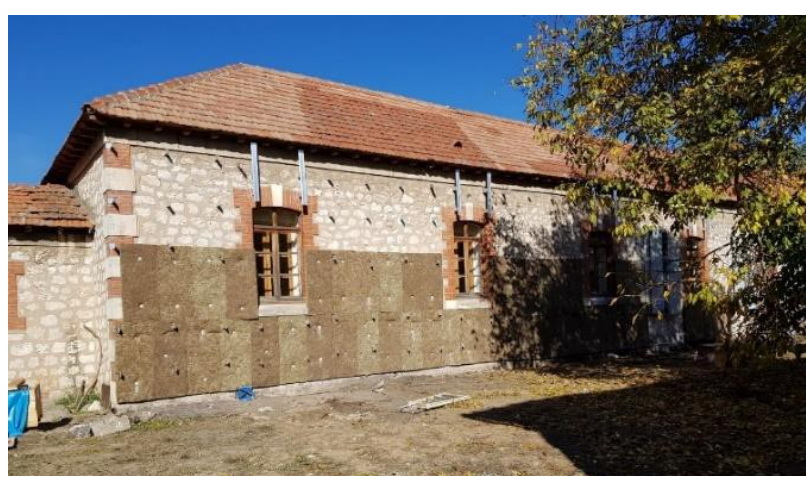

Fig. 1. Insulation layer over the existing masonry façade during the retrofit phase.

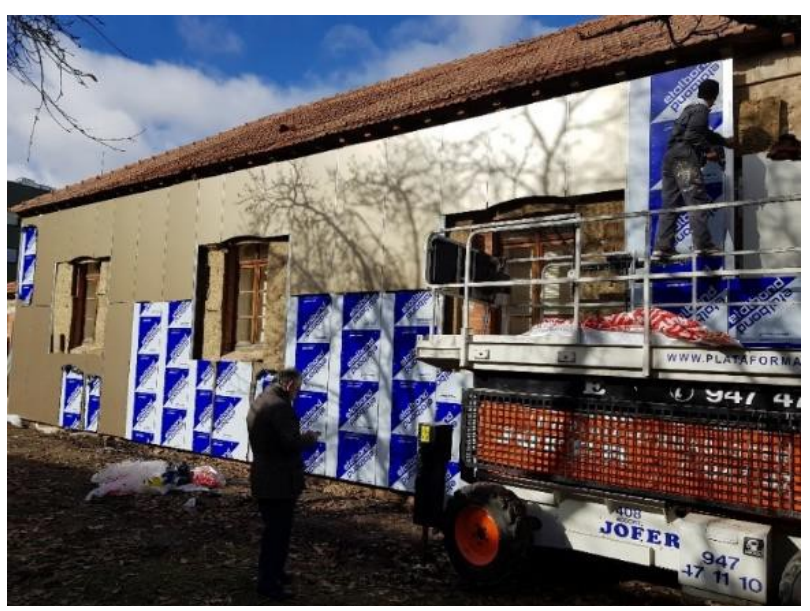

Fig. 2. Installation of the ventilated cladding system on top of the insulation layer.

The building envelope insulation was performed in December 2017.

\section{Measurement System}

The monitoring system that is deployed in the case study aims two measurement datasets: energy data and comfort conditions. In terms of energy, two rooms are monitored where the radiators' energy use is gathered. Additionally, there exists a weather station in order to provide climate conditions. This is installed on the roof of the Building 3. Table 1 summarises the variables that are interesting for the present paper, the deployed device and its precision

Table 1. Monitoring system summary

\begin{tabular}{|c|c|c|}
\hline Variable & Model (device) & Precision (error) \\
\hline Radiator energy use & Kamstrup multical & $\pm\left(0.5+\Delta \mathrm{T}_{\min } / \Delta \mathrm{T}\right) \%$ \\
\hline External temperature & 602 & $\pm 0.5^{\circ} \mathrm{C} /$ \\
and humidity & Thermokon & $\pm 2 \%$ \\
\hline Solar radiation & Apogee SP-215 & $\pm 5 \%$ \\
\hline
\end{tabular}


The thermal performance of the external walls was measured using portable equipment. Phymeas Type 7 sensors were used to measure heat flux, and temperature readings were taken with Pt100 sensors manufactured by Pironor. Readings were taken at 1-minute intervals and stored on ALMEMO 2590A data loggers. Both heat flux and temperature sensors were placed at internal surfaces, and additional temperature sensors were placed at external surfaces. All sensors were protected from solar radiation (by means of their orientation) and from the influence of thermal bridges and nearby heating sources.

\section{Measurement sequences}

This case study is presented based on data from the 2015-2019 period.

Energy use in the pre-retrofit status is taken from the period 2015-10-01 to 2017-10-31. Energy use in the post-retrofit status is taken from the period 2018-02-01 until now (still monitoring. For the purpose of this work, until 2019-10-31). U-value measurements are taken from measurements in Q1 2019. Pre-retrofit data from a North-oriented façade not retrofitted in [11], with same thickness and materials. Post-retrofit data from a Northoriented façade retrofitted in [11].

A daily summary of ambient temperature, solar irradiation and heating load is presented in figure 3 .

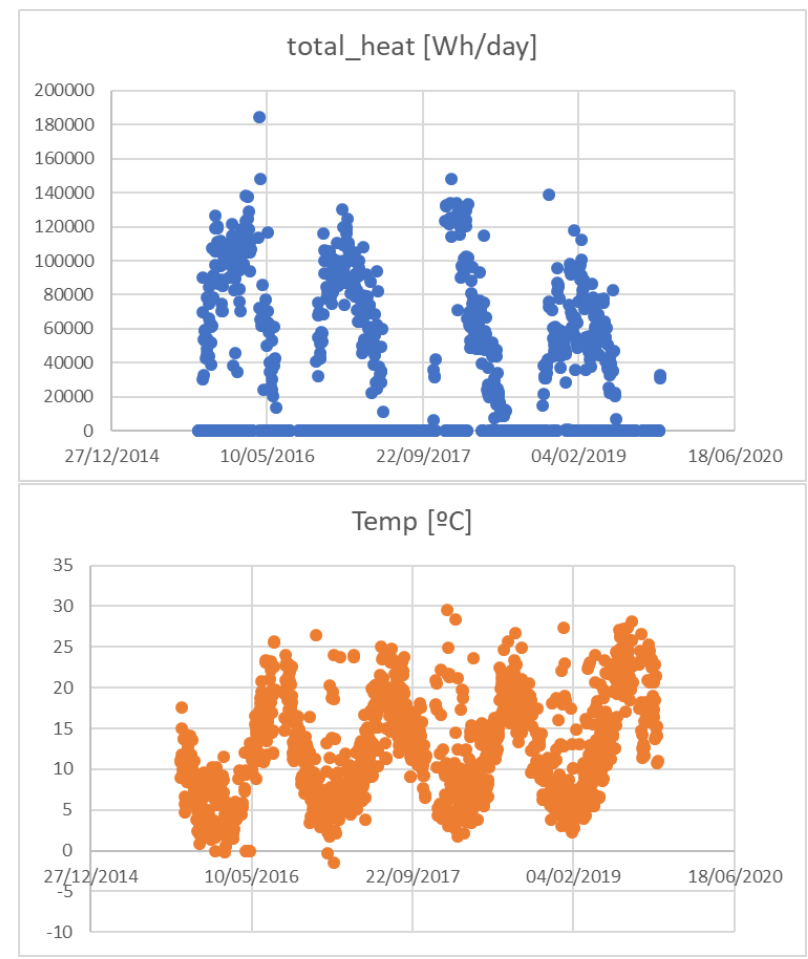

Fig. 3. Summary of measurement campaign. Heating load \& Ambient Temperature

\section{Results}

The application of the method stated in section 4 over the building and measurement campaign stated in sections 5, $6 \& 7$ results in the coefficients stated in tables below.
Table 2. Heat loss coefficient of building envelopes. Design and experimental assessment methods are considered

\begin{tabular}{|c|c|c|c|c|}
\hline \multirow{2}{*}{} & \multicolumn{2}{|c|}{$\begin{array}{c}\mathrm{HLC} \\
{[\mathrm{kWh} / \mathrm{K}]}\end{array}$} & \multicolumn{2}{c|}{ Difference } \\
\cline { 2 - 5 } & Design & Measured & $\begin{array}{c}\text { Absolute } \\
{[\mathrm{kWh} / \mathrm{K}]}\end{array}$ & $\begin{array}{c}\text { Relative } \\
{[\%]}\end{array}$ \\
\hline PRE-RETROFIT & 5.37 & 8.12 & 2.75 & $51 \%$ \\
\hline POST-RETROFIT & 1.46 & 3.67 & 2.20 & $151 \%$ \\
\hline Difference (\%) & $-73 \%$ & $-55 \%$ & & \\
\hline
\end{tabular}

Table 3. Coefficients of the energy signature process as stated in (1) and (4)

\begin{tabular}{|c|c|c|c|c|}
\hline Status & Period & $\begin{array}{c}\mathrm{C}_{1} \\
{[\mathrm{kWh} /} \\
\text { K.day] }\end{array}$ & $\begin{array}{c}\mathrm{C}_{1 / \text { HLC }} \\
{[\mathrm{Wh} /} \\
\text { K.day] }\end{array}$ & $\begin{array}{c}\mathrm{C}_{1} \text { OTHER } \\
\text { [Wh/ } \\
\text { K.day] }\end{array}$ \\
\hline Pre-retrofit & $2015-2017$ & $-9,76$ & -8.12 & 1.64 \\
\hline Post-retrofit & $2018-2019$ & $-5.31^{*}$ & -3.67 & $1.64^{*}$ \\
\hline
\end{tabular}

In table 3 , items marked with $*$ in the post-retrofit case are assumptions based on data from the pre-retrofit case. The coefficients form table 3 are used over (5) to compute for the predicted energy use in the building for the measurement periods. Results from these coefficients are presented in Table 4 and compared to the measured energy use.

Table 4. measured vs predicted energy use

\begin{tabular}{|c|c|c|c|}
\hline Performance & $\mathrm{E}_{\text {measured }}[\mathrm{MWh}]$ & $\mathrm{E}_{\text {predicted }}[\mathrm{MWh}]$ & Diff. [\%] \\
\hline Pre-retrofit & 22.83 & 19.00 & $20 \%$ \\
\hline Post-retrofit & 9.06 & 6.93 & $31 \%$ \\
\hline
\end{tabular}

The allocation of energy to the building envelopes is presented in table 5. In this table, coefficients from the pre- and post- retrofit scenarios are applied to the postretrofit data.

Table 5. computation of energy savings due to the building envelope retrofit

\begin{tabular}{|c|c|c|c|c|}
\hline \multirow[b]{2}{*}{ Type } & \multirow[b]{2}{*}{ Stage } & \multicolumn{2}{|l|}{ Heat } & \multirow[t]{2}{*}{ Unit } \\
\hline & & Total & Envelope & \\
\hline measured & $\begin{array}{l}\text { post- } \\
\text { intervention }\end{array}$ & 9.06 & & [MWh] \\
\hline predicted & $\begin{array}{l}\text { pre- } \\
\text { intervention }\end{array}$ & 8.07 & 6.93 & [MWh] \\
\hline predicted & $\begin{array}{l}\text { post- } \\
\text { intervention }\end{array}$ & 6.93 & 3.13 & [MWh] \\
\hline projected & $\begin{array}{l}\text { pre- } \\
\text { intervention }\end{array}$ & 10.73 & & [MWh] \\
\hline \multirow[b]{2}{*}{ reduction } & & 1.67 & 3.80 & [MWh] \\
\hline & & $16 \%$ & $55 \%$ & {$[\%]$} \\
\hline
\end{tabular}

Table 6. Estimation of heat load not properly attributed in the energy signature model.

\begin{tabular}{|l|l|l|l|}
\hline Type & Stage & Total Heat & Unit \\
\hline measured & post-intervention & 9.06 & {$[\mathrm{MWh}]$} \\
\hline predicted & pre-intervention & 8.07 & {$[\mathrm{MWh}]$} \\
\hline predicted & post-intervention & 6.93 & {$[\mathrm{MWh}]$} \\
\hline projected & pre-intervention & 10.73 & {$[\mathrm{MWh}]$} \\
\hline \multirow{3}{*}{$\begin{array}{l}\text { unknown } \\
\text { sources }\end{array}$} & & 2.67 & {$[\mathrm{MWh}]$} \\
\cline { 3 - 4 } & pre-intervention & $25 \%$ & {$[\%]$} \\
\cline { 2 - 4 } & & 2.13 & {$[\mathrm{MWh}]$} \\
\cline { 3 - 4 } & post-intervention & $24 \%$ & {$[\%]$} \\
\hline
\end{tabular}


The estimation of heat load not properly accounted for in the energy signature model is presented in table 6 .

\section{Discussion \& Conclusions}

The case study presented in this work outlines the need for well designed \& executed $\mathrm{M} \& \mathrm{~V}$ processes within building energy retrofit. Several specific conclusions can be drawn from this study.

First of all, the need for on-site measurement of Uvalues is found to be clear. The measured HLC value is 51 to $151 \%$ of the calculated values. This also states that approximately constant errors in absolute terms (2.2 to $2.75 \mathrm{kWh} / \mathrm{K}$ ) result in substantially greater errors in more insulated buildings such as the post-retrofit case.

The energy signature method proved to be adequate to partially capture the sensibility of the energy performance of the building towards the climate. However, the proposed regression resulted in a substantial underestimation (20 to $30 \%$ ) of the actual heating load. Although no specific reason has been found for this issue, it might have been related to the fact that the case study is an educational building. Its use results in higher heating loads on Mondays and after bank holidays or vacation periods. This fact has not issue is yet to be properly assessed in future works.

Considering the actual allocation of heat flows in buildings, the building envelope insulation retrofit resulted in a total reduction of $16 \%$ of the heating load of the building. Actually, it reduced the heating load specifically allocated to the building envelope by $55 \%$.

This heating load reduction is substantial, particularly when considered the shape of the building and that no specific intervention was performed at floor slab and roof level.

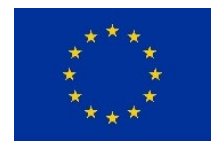

This project has received funding from the European Union's Horizon 2020 research and innovation programme under grant agreement No 768567.

\section{References}

1. https://www.europarl.europa.eu/doceo/document/T A-9-2019-0078 EN.html

2. European Commission. $\operatorname{COM}(2010) 639$ final of 10.11.2010.

3. European Commission. Directive 2010/31/EU.

4. Energy Valuation Organization, IPMVP Core concepts, 2014

5. Harris, Energy (Performance) Signatures and the First View Approach, 19 National Conference on Building Commissioning, 2011

6. ISO 9869-1:2014.

7. De Wilde, P. Aut. Constr. Vol. 41 (2014).

8. Lumbreras et Al. Energy meters in District-Heating Substations for Heat Consumption Characterization and Prediction Using Machine-Learning Techniques. Beyond 2020. Publication pending
9. ISO 9869-1:2014.

10. ASTM C1155 - 95 (2013).

11. E2VENT, h2020 Grant agreement ID: 637261

12. Zurro et Al. Comparison of theoretical heat transfer model with results from experimental monitoring installed in a refurbishment with ventilated facade. SBE-19 Thessaloniki

13. ISO 6946:2017

14. EN 410:2011

15. ISO 12631:2017

16. ASTM C $1199-14$

17. ISO 13789:2017 